\title{
Hubungan Infeksi Soil Transmitted Helminths dengan Kemampuan Kognitif, Status Nutrisi, dan Prestasi Belajar pada Anak Sekolah Dasar di Desa Sikapas Kabupaten Mandailing Natal
}

Putri Hasria Sri Murni, Munar Lubis, Isti Ilmiati Fujiati*

Departemen Ilmu Kesehatan Anak, *Departemen Kedokteran Komunitas Fakultas Kedokteran Universitas Sumatera Utara, Medan

Latar belakang. Prevalensi soil transmitted helminths (STH) pada anak di Indonesia, terutama di Provinsi Sumatera Utara, masih tinggi. Infeksi STH diduga dapat menghambat tumbuh kembang dan memengaruhi kemampuan kognitif anak.

Tujuan. Mengetahui hubungan infeksi STH dengan kemampuan kognitif, status nutrisi, dan prestasi belajar pada anak.

Metode. Penelitian potong lintang dilakukan di Desa Sikapas, Kabupaten Mandailing Natal pada bulan Maret sampai Desember 2016. Sampel adalah murid sekolah dasar yang tidak memiliki gangguan mental dan dipilih dengan metode acak sederhana. Tinja diperiksa dengan metode Kato untuk menilai infeksi STH. Dilakukan pengumpulan data antropometri dan rerata nilai ujian untuk semua mata pelajaran. Kemampuan kognitif dinilai dengan metode WISC IV. Analisis dilakukan dengan uji Chi square dan uji Mann Whitney dengan tingkat kepercayaan 95\%. Nilai $\mathrm{p}<0,05$ dianggap signifikan.

Hasil. Delapan puluh tujuh sampel diikutsertakan dengan rerata usia 10,2 (SB 1,75) tahun. Kami menemukan angka prevalensi yang tinggi untuk anak dengan infeksi STH (70,1\%). Anak dengan infeksi STH memiliki status gizi yang lebih baik daripada anak tanpa infeksi STH dengan rerata peringkat 44,31 vs 43,27 , tetapi tidak signifikan secara statistik $(\mathrm{p}=0,816)$. Anak dengan infeksi STH memiliki rerata peringkat kemampuan kognitif yang relatif lebih rendah daripada anak tanpa infeksi STH (43,77 vs 44,54), tetapi tidak signifikan secara statistik $(\mathrm{p}=0,885)$. Prestasi belajar anak dengan infeksi STH lebih tinggi daripada anak tanpa infeksi $\mathrm{STH}$, tetapi tidak signifikan secara statistik $(\mathrm{p}=0,317)$.

Kesimpulan. Tidak terdapat hubungan yang signifikan antara infeksi STH dengan status nutrisi, kemampuan kognitif, dan prestasi belajar pada anak di komunitas ini. Sari Pediatri 2018;19(5):279-83

Kata kunci: soil transmitted helminths, anak, kognitif, status nutrisi, prestasi belajar

\section{Association between soil transmitted helminths infection and cognitive performance, nutritional status, and academic achievement in elementary school children in Sikapas village, Mandailing Natal regency}

Putri Hasria Sri Murni, Munar Lubis, Isti Ilmiati Fujiati*

Background. The prevalence of soil transmitted helminths (STH) among children in Indonesia, particularly in North Sumatera Province, remains high. Soil transmitted helmints infection may cause delay in children's growth and development and lower their cognitive performance.

Objective. To determine the association between STH infection and cognitive performance, nutritional status, and academic achievement.

Methods. Cross-sectional study was conducted in Sikapas Village, Mandailing Natal Regency from March to December 2016. Samples were students of elementary school without mental disorders that obtained by simple random sampling. Stool samples were examined using Kato Katz smear method to determine STH infection. Anthropometric data and mean grade points from all school subjects were collected. Cognitive performance was measured using WISC IV method. Analyses were done using Chi-square test and Mann-Whitney U test with 95\% Confidence Interval. A p value of $<0.05$ was considered to be statistically significant.

Results. Eighty seven samples were enrolled with mean age 10.2 (SD 1.75) years old. We found high prevalence rate of children with STH infection (70.1\%). The children with STH infection had better nutritional status compared to children without STH infection with mean rank of 44.31 vs 43.27 , but not statistically significant $(\mathrm{p}=0.816)$. The children with STH infection had relatively lower mean rank cognitive performance than children without STH infection ( 43.77 vs 44.54$)$, but not statistically significant ( $\mathrm{p}=0.885)$. The academic achievement of children with STH infection was higher than uninfected children, but not statistically significant ( $\mathrm{p}=0.317$ ). Conclusion. There is no significant association between STH infection and nutritional status, cognitive performance, and academic achievement among children in this community. Sari Pediatri 2018;19(5):279-83

Keywords: soil transmitted helminths, children; cognitive, nutritional status, academic achievement

Alamat korespondensi: Dr. Putri Hasria Sri Murni. Departemen Ilmu Kesehatan Anak Fakultas Kedokteran Universitas Sumatera Utara, Jl. Dr. Mansyur No. 66, Medan 20154. Email: putrihasria@gmail.com. 
Putri Hasria Sri Murni dkk: Hubungan infeksi STH dengan kemampuan kognitif, status nutrisi, dan prestasi belajar

$N$ glected tropical diseases (NTDs) berkembang di daerah yang miskin, di area terpencil, pedesaan, dan daerah kumuh perkotaan. Termasuk dalam NTDs di antaranya infeksi soil transmitted helminths (STH), schistosomiasis, filariasis limfatik, dan onchocerciasis. ${ }^{1}$ Soil transmitted helminths merupakan sekelompok parasit nematoda penyebab infeksi pada manusia akibat kontak dengan telur parasit atau larva yang berkembang di dalam tanah bersuhu hangat dan lembab di negara tropis dan subtropis. ${ }^{2,3}$ Jenis cacing STH yang sering ditemukan, yaitu cacing gelang (Ascaris lumbricoides), cacing cambuk (Trichuris trichiura), dan cacing tambang (Ancylostoma duodenale dan Necator americanus). ${ }^{1,2,4}$ Pada tahun 2001, World Health Assembly, dengan resolusi 54,19, menetapkan target global pengobatan $75 \%$ anak usia sekolah (biasanya dinyatakan sebagai anak berusia 5 hingga 14 tahun) berisiko menderita infeksi STH sampai dengan tahun 2010. ${ }^{1}$ World Health Organization (WHO) tahun 2012 mengatakan bahwa lebih dari 2 milyar orang di seluruh dunia terinfeksi STH.

Kebutuhan tatalaksana STH di dunia, 42\% terdapat di negara wilayah Asia Selatan dan Tenggara, yaitu 64\% berasal dari India, 15\% berasal dari Indonesia, dan 13\% berasal dari Bangladesh. ${ }^{5}$ Wilayah ini merupakan lokasi terbesar pelaksanaan program pencegahan infeksi STH. Menurut Kementerian Kesehatan RI (2011), salah satu masalah kesehatan yang sering dialami anak usia sekolah adalah kecacingan. ${ }^{6}$ Hasil Survey kecacingan 2009 di Indonesia oleh Ditjen P2PL menyebutkan 31,8\% siswa Sekolah Dasar (SD) menderita kecacingan. Dalam laporan hasil survey prevalensi infeksi cacing pada 10 provinsi tahun 2004, Sumatera Utara menduduki peringkat ke-3 $(60,4 \%)$ dalam hal penyakit cacingan setelah Sumatera Barat $(82,3 \%)$ dan Nusa Tenggara Barat $(83,6 \%)^{7}$

Dampak penyakit STH terutama dikaitkan dengan masalah kronik dan berbahaya bagi kesehatan dan kualitas hidup anak yang terinfeksi. Infeksi kecacingan yang berat akan menganggu pertumbuhan fisik dan kemampuan kognitif. Infeksi kecacingan yang berat juga merupakan penyebab terjadinya defisiensi mikronutrien termasuk anemia defisiensi besi (terutama oleh jenis Ancylostoma duodenale dan Necator americanus) sehingga performa anak di sekolah menurun dan sering tidak datang ke sekolah., ${ }^{2,8,9}$ Tujuan dari penelitian ini adalah untuk mengetahui hubungan infeksi STH dengan kemampuan kognitif, status nutrisi, dan prestasi belajar pada anak.

\section{Metode}

Studi analitik dengan desain potong lintang dilakukan di 384 sekolah dasar di Desa Sikapas, Kabupaten Mandailing Natal, Sumatera Utara dari bulan Maret sampai Desember 2016. Subjek dipilih dengan teknik simple random sampling. Anak usia sekolah dasar dengan atau tanpa infeksi STH diikutsertakan. Pasien dengan gangguan jiwa dikeluarkan. Infeksi cacing yang ditularkan melalui tanah adalah deteksi telur dari satu atau lebih jenis STH, yaitu Ascaris lumbricoides, Trichuris trichura, Necator americanus, atau Ancylostoma duodenale di tinja anak usia sekolah dasar di Sikapas dengan metode hapusan Kato Katz. ${ }^{10}$

Sampel tinja dikumpulkan dari anak usia sekolah dasar. Metode hapusan Kato Katz dilakukan untuk mendeteksi telur STH. Status gizi dinilai menggunakan data antropometrik (tinggi dan berat badan) ${ }^{11}$ dari semua subjek di sekolah. Kemampuan kognitif diukur dengan menggunakan metode WISC IV. ${ }^{12}$ Prestasi belajar dibagi menjadi tiga kategori, yaitu baik (nilai $\geq 80$ ), cukup (nilai 60-79,9) dan kurang (nilai $<60$ ). Penelitian ini disetujui oleh Komite Etik Penelitian Kesehatan Fakultas Kedokteran Universitas Sumatera Utara. Orang tua dari anak diminta untuk memberikan persetujuan untuk mengikuti penelitian.

Data deskriptif dinyatakan sebagai rerata (simpangan baku). Hubungan antara infeksi STH dan kemampuan kognitif, status gizi ditentukan dengan menggunakan analisis bivariat (uji Mann-Whitney $U$ ) dengan interval konfidensi 95\%. Analisis bivariat (uji Chi-square) digunakan untuk mengetahui hubungan antara infeksi STH dan prestasi belajar. Nilai $\mathrm{p}<0,05$ dianggap signifikan secara statistik. Analisis statistik dilakukan dengan program SPSS versi 20.

\section{Hasil}

Dari 323 anak di sekolah dasar, hanya ada 280 anak yang datang ke sekolah. Keesokan harinya, 54 anak menolak untuk berpartisipasi dan 26 anak tidak hadir saat mengumpulkan tinja. Dari 200 anak yang diberi botol tinja, ada 13 anak yang tidak membawa sampel tinja dan 7 anak yang tidak hadir. Seratus delapan puluh anak diacak. Dari 87 anak yang berpartisipasi dalam penelitian ini, terdapat $61(70,1 \%)$ anak dengan infeksi STH dan 26 (29,9\%) anak tanpa infeksi STH. Lima puluh dua (59\%) anak adalah laki-laki dan 
$35(40,2 \%)$ adalah perempuan. Sampel penelitian memiliki rata-rata usia 10,2 tahun.

Anak yang tidak terinfeksi STH cenderung lebih berat, lebih tinggi dan memiliki lingkar kepala yang lebih besar daripada anak yang terinfeksi (Tabel 1). Namun, persentase anak yang terinfeksi STH lebih mungkin memiliki status gizi yang sedikit lebih baik daripada anak yang tidak terinfeksi. Rerata nilai rapor pada anak dengan infeksi STH sedikit lebih tinggi daripada mereka yang tidak terinfeksi STH. Karakteristik latar belakang sampel berdasarkan status infeksi tertera pada Tabel 1. Rerata peringkat tingkat kemampuan kognitif anak dengan infeksi STH lebih rendah dibandingkan dengan kelompok tanpa infeksi STH $(43,77$ vs 44,54$)$, tetapi tidak signifikan secara statistik ( $\mathrm{p}=0,885)$. Hubungan antara infeksi STH dan kemampuan kognitif tertera pada Tabel 2.

Kelompok dengan infeksi STH mempunyai rerata peringkat status nutrisi yang lebih tinggi dibandingkan dengan kelompok tanpa infeksi STH (44,31 vs 43,27), tetapi tidak signifikan secara statistik $(\mathrm{p}=0,816)$. Hubungan antara infeksi STH dan status gizi tertera pada Tabel 3. Prestasi belajar anak dengan infeksi STH lebih tinggi daripada anak tanpa infeksi STH, tetapi tidak signifikan secara statistik $(\mathrm{p}=0,317)$. Hubungan antara infeksi STH dan prestasi belajar tertera pada Tabel 4.

Tabel 1. Data demografik subjek penelitian

\begin{tabular}{lcc}
\hline Karakteristik & Infeksi STH & Tidak terinfeksi STH \\
$\mathrm{n}=61$ & 26 \\
\hline Rerata berat badan, kg (SB) & $24,4(5,08)$ & $24,6(5,54)$ \\
Rerata tinggi badan, cm (SB) & $125,2(10,82)$ & $127,5(11,1)$ \\
Rerata lingkar lengan, cm (SB) & $17,1(1,78)$ & $17,2(1,63)$ \\
Rerata BB/TB, \% (SB) & $96,0(11,65)$ & $93,5(9,78)$ \\
Status nutrisi, $\mathrm{n}(\%)$ & & \\
Buruk & $2(3,2)$ & $1(3,8)$ \\
Kurang & $18(29,5)$ & $8(30,7)$ \\
Baik & $36(59)$ & $15(57,6)$ \\
Overweight & $3(4,9)$ & $2(7,6)$ \\
Obesitas & $2(3,2)$ & $0(0)$ \\
Kemampuan kognitif, n (\%) & \\
Mental defective & $7(11,4)$ & $6(23)$ \\
Borderline & $23(37,7)$ & $6(23)$ \\
Low average & $14(22,9)$ & $6(23)$ \\
Average & $16(26,2)$ & $7(26,9)$ \\
Bright normal & $1(1,6)$ & $0(0)$ \\
Superior & $0(0)$ & $1(3,8)$ \\
Rerata nilai rapor, (SB) & $75,2(5,33)$ & $75,1(7,06)$ \\
Prestasi belajar, n (\%) & & \\
Baik & $14(22,9)$ & $9(34,6)$ \\
Kurang & $41(67,2)$ & $13(50)$ \\
Cukup & $6(9,8)$ & $4(15,3)$ \\
\hline
\end{tabular}

Tabel 2. Hubungan antara infeksi STH dengan kemampuan kognitif

\begin{tabular}{|c|c|c|c|c|c|c|c|c|}
\hline \multirow[t]{3}{*}{ Infeksi STH } & \multicolumn{6}{|c|}{ Kemampuan kognitif } & \multirow[t]{3}{*}{$\mathrm{p}^{*}$} & \multirow[t]{3}{*}{ IK95\% } \\
\hline & $\begin{array}{l}\text { Mental } \\
\text { defective }\end{array}$ & Borderline & $\begin{array}{l}\text { Low } \\
\text { average }\end{array}$ & Average & $\begin{array}{l}\text { Bright } \\
\text { normal }\end{array}$ & Superior & & \\
\hline & n $(\%)$ & $\mathrm{n}(\%)$ & $\mathrm{n}(\%)$ & $\mathrm{n}(\%)$ & $\mathrm{n}(\%)$ & $\mathrm{n}(\%)$ & & \\
\hline $\mathrm{Ya}$ & $7(53,8)$ & $23(79,3)$ & $14(70)$ & $16(69,6)$ & $1(100)$ & $0 \quad(0)$ & 0,885 & $(0,818-0,952)$ \\
\hline Tidak & $6(46,2)$ & $6(20,7)$ & $6(30)$ & $7(30,4)$ & $0(0)$ & $1(100)$ & & \\
\hline
\end{tabular}

*uji Mann - Whitney,Mean rank Infeksi STH 43,77 dan tidak infeksi STH 44,54 
Putri Hasria Sri Murni dkk: Hubungan infeksi STH dengan kemampuan kognitif, status nutrisi, dan prestasi belajar

Tabel 3. Hubungan antara infeksi STH dengan status nutrisi

\begin{tabular}{|c|c|c|c|c|c|c|c|}
\hline \multirow[t]{3}{*}{ Infeksi STH } & \multicolumn{5}{|c|}{ Status nutrisi } & \multirow[t]{3}{*}{$\mathrm{p}^{*}$} & \multirow[t]{3}{*}{$95 \%$ IK } \\
\hline & Buruk & Kurang & Baik & Overweight & Obesitas & & \\
\hline & $\mathrm{n}(\%)$ & $\mathrm{n}(\%)$ & $\mathrm{n}(\%)$ & $\mathrm{n}(\%)$ & $\mathrm{n}(\%)$ & & \\
\hline Ya & $2(66,7)$ & $18(69,2)$ & $36(70,6)$ & $3(60)$ & $2(100)$ & 0,816 & $(0,735-0,897)$ \\
\hline Tidak & $1(33,3)$ & $8(30,8)$ & $15(29,4)$ & $2(40)$ & $0(0)$ & & \\
\hline
\end{tabular}

*uji Mann - Whitney, Mean Rank Infeksi STH 44,31 dan tidak infeksi STH 43,27

Tabel 4. Hubungan antara infeksi STH dengan prestasi belajar

\begin{tabular}{lcccc}
\hline Infeksi STH & \multicolumn{3}{c}{ Prestasi } & \multirow{2}{*}{$\mathrm{p}^{*}$} \\
\cline { 2 - 4 } & $\mathrm{Baik}$ & Kurang & Cukup & \\
\cline { 2 - 4 } & $\mathrm{n}(\%)$ & $\mathrm{n}(\%)$ & $\mathrm{n}(\%)$ & 0,317 \\
Ya & $14(60,9)$ & $41(75,9)$ & $6(60)$ & \\
\hline
\end{tabular}

*uji Chi square

\section{Pembahasan}

Penelitian pada anak dengan infeksi STH ini dilaporkan angka prevalensi $70,1 \%$. Hal tersebut kemungkinan disebabkan oleh infeksi STH endemik yang tinggi di lokasi penelitian dengan mayoritas penduduk bekerja di perkebunan. Selain itu, akses terhadap pelayanan kesehatan tidak memadai menyebabkan pemberian obat cacing sulit. Temuan ini berbeda secara bermakna dari penelitian sebelumnya di Cina dengan angka prevalensi $42 \% .{ }^{13}$

Sebuah tinjauan sistematis terhadap 45 penelitian pada tahun 2015 oleh Taylor dkk ${ }^{14}$ melaporkan bahwa mengobati anak yang terinfeksi STH dengan obat cacing dosis tunggal dapat meningkatkan berat badan selama satu sampai enam bulan berikutnya. Hasil yang bervariasi dari studi melaporkan kenaikan berat badan 0,2 kg sampai 1,3 $\mathrm{kg}$. Tinjauan sistematis lainnya terhadap 42 penelitian pada tahun 2012 oleh Taylor $\mathrm{dkk}^{14}$ melaporkan bahwa mengobati anak yang terinfeksi STH dengan obat cacing dosis tunggal dapat meningkatkan berat badan $(0,58 \mathrm{~kg}$, IK 95\% 0,40-0,76) dan meningkatkan kadar hemoglobin (0,37 g/dL, IK 95\% 0,1 sampai 0,64). Studi di Cina oleh Liu $\mathrm{dkk}^{13}$ menemukan hasil yang serupa dengan tinjauan sistematis. Studi ini menemukan hubungan antara infeksi STH dengan pertumbuhan linier dan penambahan berat badan. Namun, infeksi disebabkan oleh lebih dari satu spesies STH. Mereka juga melaporkan bahwa kadar hemoglobin pada anak dengan infeksi STH lebih rendah daripada anak yang tidak terinfeksi. Dalam penelitian kami tidak ada hubungan yang bermakna antara infeksi STH dan status gizi.

Dua tinjauan sistematis oleh Taylor dkk melaporkan hubungan antara infeksi STH dan kemampuan kognitif. ${ }^{14}$ Studi oleh Ebenezer dkk ${ }^{15}$ menunjukkan tidak ada hubungan yang bermakna antara infeksi STH dan kemampuan kognitif. Studi kohort oleh Ezeamama $\mathrm{dkk}^{16}$ melaporkan hubungan positif antara kemampuan kognitif dan infeksi STH dengan menyebabkan anemia defisiensi besi, inflamasi, status gizi menurun, dan nyeri perut. Mereka melakukan studi prospektif tentang infeksi STH (terutama Schistosoma japonicum) dengan kemampuan kognitif. Studi tersebut menunjukkan bahwa mengurangi intensitas dan frekuensi infeksi beberapa spesies cacing dan multi-spesies STH mungkin memiliki manfaat jangka panjang untuk kemampuan kognitif anak yang terkena dampak. Sebuah studi di Cina oleh Liu dkk ${ }^{13}$ melaporkan bahwa anak yang terinfeksi satu atau lebih STH memiliki kemampuan kognitif yang lebih buruk daripada anak yang tidak terinfeksi. Meskipun tidak kausal, penelitian ini juga menunjukkan bukti bahwa anak dengan infeksi Trichuris, baik infeksi dengan Trichuris saja atau koinfeksi dengan Trichuris dan Ascaris, memiliki kemampuan kognitif yang lebih buruk daripada anak yang tidak terinfeksi yang hanya terinfeksi dengan Ascaris. Dalam penelitian kami, tidak ada hubungan bermakna antara infeksi STH dan kemampuan kognitif. 
Tinjauan sistematis oleh Taylor $\mathrm{dkk}^{14}$ menemukan bukti dalam kaitannya dengan kemampuan dan kehadiran anak di sekolah umumnya buruk, tanpa efek yang konsisten dan jelas. Sebuah studi oleh Ebenezer $\mathrm{dkk}^{15}$ untuk menilai kemampuan di sekolah berdasarkan dua mata pelajaran, yaitu bahasa dan matematika. Mereka tidak menemukan hubungan antara infeksi STH dan kemampuan di sekolah. Penelitian lain oleh Liu dkk ${ }^{13}$ melaporkan bahwa anak yang terinfeksi STH memiliki kemampuan di sekolah yang lebih buruk daripada anak yang tidak terinfeksi. Dalam penelitian kami, tidak ada hubungan yang bermakna antara infeksi STH dan prestasi belajar.

\section{Kesimpulan}

Tidak ada hubungan yang signifikan antara infeksi STH dan status gizi, kemampuan kognitif, dan prestasi belajar pada anak dari hasil penelitian pada anakanak di Desa Sikapas, Kabupaten Mandailing Natal, Sumatera Utara.

\section{Daftar pustaka}

1. World Health Organization. Helminth control in school-age children, a guide for managers of control programmes. Second Edition. France: WHO Press;2011.

2. Bethony J, Brooker S, Albonico M, Geiger SM, Loukas A, Diemert D, dkk. Soil-transmitted helminth infections: ascariasis, trichuriasis, and hookworm. Lancet 2006;367:1521-32.

3. WHO. Deworming for health and development. Report of the third global meeting of the partners for parasite control. Geneva: World Health Organization; 2005.

4. Babatunde SK, Adedayo MR, Ajiboye AE, Sunday O, Ameen N. Soil-transmitted helminth infections among school children in rural communities of Moro Local Government Area, Kwara State, Nigeria. Afr J Microbiol Res 2013;7:514-53.

5. World Health Organization. Soil-transmitted helminthiases, eliminating soil-transmitted helminthiases as a public health problem in children: progress report 2001-2010 and strategic plan 2011-2020. France: WHO Press;2012.

6. Kementerian Kesehatan RI. Pusat Data dan Informasi Profil Kesehatan Indonesia 2010. Jakarta: Kementerian Kesehatan RI;
2011.

7. Kementerian Kesehatan RI. Direktorat Jenderal PP dan PL. Pedoman Pengendalian Kecacingan. Jakarta: Kementerian Kesehatan RI;2012.

8. Hughes S, Kelly P. Interactions of malnutrition and immune impairment, with specific reference to immunity against parasites. Parasites Immunol 2006;28:577-88.

9. Hotez PJ, Brindley PJ, Bethony JM, King CH, Pearce EJ, Jacobson J. Helminth infections: the great neglected tropical diseases. J Clin Invest 2008;118:1311-21.

10. Glinz D, Silue KD, Knopp S, Lohourignon LK, Yao KP, Steinmann P, dkk. Comparing diagnostic accuracy of KatoKatz Agar Plate, Ether-Concentration, and FLOTAC for schiscosoma mansoni and soil-transmitted helminth. PLos Negl Trop Dis 2010;4:e754.

11. Sjarif DR. Prinsip asuhan nutrisi pada anak. Sjarif DR, Lestari ED, Mexitalia Maria, Nasar SS, penyunting. Buku Ajar Nutrisi Pediatrik dan Penyakit Metabolik. Jakarta: Ikatan Dokter Anak Indonesia 2011.h.36-48.

12. Rostami R, Sadeghi V, Zarei J, Haddadi P, Mohazzab-Torabi S, Salamati P. Concurrent validity of persian version of wechsler intelligence scale for children-fourth edition and cognitive assessment system in patients with learning disorder. Iran J Pediatr 2013;23:183-8.

13. Liu C, Luo R, Yi H, Zhang LX, Li S, Bai Y, dkk. Soiltransmitted helminths in Southwestern China: a crosssectional study of links to cognitive ability, nutrition, and school performance among children. PLoS Negl Trop Dis 2015;9:e0003877.

14. Taylor-Robinson DC, Maayan N, Soares-Weiser K, Donegan $S$, Garner P. Deworming drugs for soil-transmitted intestinal worms in children: effects on nutrirional indicators, haemoglobin, and school performance (review). Cochrane Database of Syst Rev 2015;7:CD000371.

15. Ebenezer R, Gunawardena K, Kumarendran B, Pathmeswaran A, Jukes MCH, Drake LJ, dkk. Cluster-randomized trial of the impact of the impact of school-based deworming and iron supplementation on the cognitive abilities of schoolchildren in Sri Lanka's plantation sector. Trop Med Int Health 2013;18:942-51.

16. Ezeamama AE, McGarvey ST, Hogan J, Lapane KL, Bellinger DC, Acosta LP, dkk. Treatment for Schistosoma japonicum, reduction of intestinal parasite load, and cognitive test score improvements in school-aged children. PLoS Negl Trop Dis 2012;6:e1634. 